\title{
A vueltas con el legado histórico del Imperio
}

Fernando Gómez

Stanford University

Con ocasión de las últimas publicaciones de H. Kamen y Samuel P. Huntington se analizan las corrientes historiográficas actuales en los Estados Unidos en torno a los "estudios imperiales".

PALABRAS ClAVE: Imperio, España, Estados Unidos, Legado histórico

The last works of H. Kamen and Samuel P. Huntington allows the author to analyze the recent historiography on "imperial studies" in the USA.

KEYWORDS: K. W: Empire, Spain, USA, Historical legacy

\section{El imperio español}

Los comienzos del siglo veintiuno parecen estar propiciando, dentro y fuera de ambientes universitarios estadounidenses, un rebrote del deseo de traer a la memoria histórica algunas de las grandes narrativas de ayer y de hoy, ineludiblemente al vuelo de algunos avatares como pueden ser el conflicto bélico en Iraq. Junto a los "estudios globales," los "estudios imperiales," presentan, como sería de esperar, una variada gama de posiciones ideológicas desde las "contestatarias," donde un libro como Empire de Michael Hardt y Antonio Negri' sobresale con todos sus aciertos y puntos flacos, hasta las "pragmáticas," por ejemplo, Colossus: The Price of America's Empire de Niall Ferguson, ${ }^{2}$ sin olvidarnos de los representantes neo-Straussianos próximos a la actual administración estadounidense, tanto si gustan para sí el concepto de "imperio" o lo atribuyen a los otros. Grandes problemáticas vienen al aire imperial: la historia de los poderosos, las intrahistorias subalternas, la historia del capitalismo y sus (im-)posibles alternativas, la historia de los imperios occidentales, la posible fuerza del legado postcolonial. En este vasto panorama hay que insertar la actualidad de la narrativa histórica incluida en Empire: How Spain Became a World Power de Henry Kamen. ${ }^{3}$

1 Hardt, M. y Negri, A: Empire, Cambridge, Harvard UP, 2000.

2 Ferguson, N: Colossus: The Price of America's Empire, New York, Penguin Press, 2004.

3 Kamen, H: Empire: How Spain Became a World Power, New York, HarperCollins Publishers, 2003. 
Este libro serio y trabajado representa una cierta "vuelta al origen" de la visibilidad "hispana," o "latina," en un contexto internacional, si no el "único" origen, al menos sí un buen candidato entre otros que nos puedan ayudar a acercarnos a visiones de espacios-tiempos amplias. Kamen nos presenta, una vez más, el legado del "siglo de oro" de esa criatura histórica tan aparentemente distante como es el "imperio español". El lector paciente de este libro de 600 páginas encontrará que la gran distancia entre la historicidad del imperio hispano y la actualidad de otros imperios, se achicaría a poco que se insista, como si de un espejismo se tratase. Darse cuenta de lo incierto de este espejismo de mala distancia, o indiferencia del ayer para con lo que llamamos el hoy, constituye un logro de la prosa de Kamen; prosa, por otro lado, un tanto escueta, modesta, que no llama la atención sobre sí misma, y que se presenta eminentemente descriptiva, sin afán de entrar en polémicas de ningún tipo. Y esto, tal vez, tenga que ver con un modo comedido, "objetivo," "imparcial," neutro, un tanto convencional, e insatisfactorio - al menos de parte de este lector- que tiene que ver con una doble evasión siguiente: rehúsar explicitar el modus operandi de este historiar, y rehusar enmarcar este quehacer de reconstrucción historiográfica dentro de (in-)visibles tradiciones con todas sus problemáticas, tensiones, insistencias u olvidos, y mucho menos dentro de las ideologías dispares de la teoría de la historia al respecto de la gigantomaquia imperial hispana de trescientos años enredada entre Asia, América, Europa y Africa. Hay, entonces, algo de retraimiento epistemológico en este historicismo a propósito de una ontología imperial/ista que también se desdice en todo momento de una serie de contextualizaciones geopolíticas de ayer y de hoy. No hay aparente deseo de comparación ni contraste entre modalidades imperiales. Con esta salvedad inicial, Kamen posee un encomiable afán de historia totalizante, casi Braudelesco, ahí está a la vista de todos su producción intelectual.

Hay un fuerte impulso ecléctico de querer tocar muchas cosas pero sin querer casarse con ninguna: hechos de diplomacia, hechos de reyes y sus guerras, chequeras de mercaderes, exploraciones americanas y filipinas, luchas de religión, redes de comercio, piratas y fronteras poco fiables, culturas en contacto, desconcierto de lenguas dispares, etc. Tras la lectura de este libro abultado el lector fiel tendrá una cierta sensación de que esto es un cajón de sastre. Y esto tal vez tenga que ver con un eclecticismo metodológico implícito. El quehacer historiográfico, por parte de este autor de origen británico afincado en tierras catalanas, se encara con la "extranjería" fundamental del imperio hispano de una manera no redonda. 
Y tal vez no se busque la redondez. Empire: How Spain Became a World Power no es propiamente una historia intelectual o de las ideas religiosas, a la manera de un Bataillon, ni una historia económica, como en Carande, Ruiz Martín, o Vicens Vives, ni una historia "fronteriza" a la manera de Bolton o Turner. Empire: How Spain Became a World Power constituye, en esencia, una historia de hechos conflictivos y expansionistas, y sus diplomacias, en el patio de vecinos de los más poderosos. Y tal vez sea lícito llamar esta modalidad historiográfica hegeliana, o incluso Kissingeriana, aun cuando no haya triunfalismos visibles por parte de Kamen. Las maneras historiográficas de Kamen en todo caso son equiparables, si bien dentro de un marco más restringido, a la de un J. M. Roberts en su The Pelican History of the World. ${ }^{4}$ Tal vez se puede calificar a Kamen de acercamiento eurocentrista sin vanaglorias. Lo de "imperial" lo vemos cercano a la visión elitista de grupos de poder administrativo y financiero de alguien como Giovanni Arrighi ${ }^{5}$, a quien Kamen no cita, por ejemplo en su impresionante The Long Twentieth Century, ${ }^{6}$ si bien se marcan diferencias con el "padre" de este mundo de sistema-mundo, Immanuel Wallerstein, de una manera puntual, superficial. ${ }^{7}$ El eje administrativo constituiría el fundamento burocrático, si se quiere, del "imperio," aun cuando se hable del fuego fatuo, o de la quimera imperial. ${ }^{8}$

La lógica secuencial de la narrativa de Kamen se apoya en rastreos intertextualistas. Hay ecos o resabios rankeanos sobre la reconstrucción de "lo que realmente pasó". ${ }^{9}$ La narrativa de Kamen va gustosa a la montaña de esta especificidad si bien de una manera eminentemente descriptiva. La historia aquí la hacen sólo los historiadores. En cualquier caso, eso de "lo que pasó," al menos según la narración voluminosa de nuestro autor, son, fundamentalmente, los hechos de armas y las letras oficiales, los decires de reyes y reinas y sus cronistas, los tratados y acuerdos de estado, lo que hacen los hombres, y no lo que hacen las mujeres. Si el impulso narrador de Kamen sigue fielmente la trayectoria del expansionismo europeo de la época del Renacimiento, de la primera modernidad, o el crecimiento del super-estado transnacional de hegemonía hispana, no hay cercanía a la posible disidencia (Latino-)Americanista con respecto a ciertas empresas

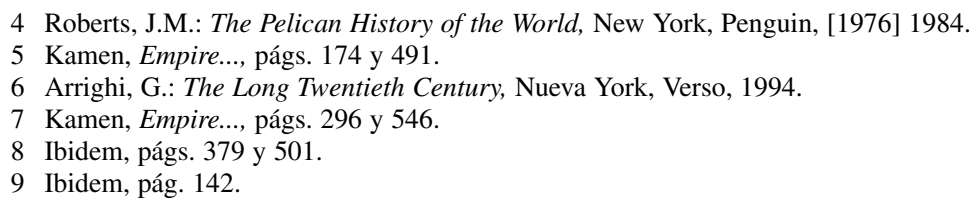


propias de un universalismo occidental/izante, pensemos en un Enrique Dussel o en un Walter Mignolo (consúltense algunas posibilidades en el libro en honor al primero, Thinking from the Underside of History: Enrique Dussel's Philosophy of Liberation). ${ }^{10}$

En Empire: How Spain Became a World Power Kamen se apunta a cierta moda, la de la modalidad sociohistórica que podemos llamar antropológica, identitario-culturalista, lo que se puede abreviar con la fórmula, un tanto gastada ya a estas alturas, de las "culturas en contacto y conflicto", ${ }^{11}$ especialmente en relación al capítulo octavo, "Identities and the Civilizing Mission," que se nos antoja de los menos convincentes. No vemos bien como el lenguaje de "cultura" e "identidad" nos puede ayudar a clarificar la posible identidad cultural imperial. Y esto se hace, por un lado con el abandono generalizado del lenguaje de choques de "civilización," que se encuentra ya en un Toynbee o en un Braudel, por ejemplo, precediendo a autores como Francis Fukujama, Samuel Huntington o Robert Kagan, y por otro lado, sin una insistencia en un rastreo pormenorizado en el legado del historicismo existencialista de las tres religiones del libro sagrado de Américo Castro, a quien sin embargo se cita. No se ve bien qué es lo que se gana "descabalgando" el imperio de la altura de la "civilización" a las bajuras de la "cultura." El capítulo once, llamado "el silencio de Pizarro," constituye lo que podríamos llamar un "giro lingüístico" con un cierto énfasis en las supuestas fallas comunicacionales de algunos de los mánagers del imperio hispano. Esta "conclusión," nos atrevemos a decir, contiene un impulso axiológico un tanto pobre, puesto que no se puede enmarcar en la explicitación de unas problemáticas que no han salido a la luz en los cientos de páginas anteriores. Recuperamos la imagen anterior: si el ovillo narrativo de este historicismo está cortado en varios pedazos y éstos están dentro y fuera del cajón de sastre, y si el sastre no nos cuenta qué tipo de vestido tiene en mente para vestir las carnes magras del emperador, puesto que hay varios diseños superpuestos sobre la mesa, no van a poder los lectores coser, componer y tensar los hilos dispersos, los pedazos de tela, los varios diseños, al final de este libro mayúsculo. $\mathrm{O}$ al menos este lector, no pudo. ¿Cómo, y para qué, y por qué? Esto queda en el aire del silencio epistemológico de nuestro historiador. Y tal vez sea la erosión de la "mitología", ${ }^{2}$ así la califica Kamen, la que constituye posiblemente la tesis central del libro. A ella retornaremos.

10 Editado por Linda Martín Alcoff y Eduardo Mendieta, Rowman and Littlefield, 2000.

11 Ibidem, págs. 159, 274, 339-41, 420, 499, 502.

12 Ibidem págs. 480, 507, 509. 
La narrativa del libro discurre así —un tanto descentrada—si bien de una manera temporal lineal, episodio tras episodio, sección tras sección, desde la fecha de 1492 hasta 1763, y siempre dentro de un marco de referencia fundamental no problematizado, que es, sin muchas sorpresas, el occidental. ${ }^{13}$ Este es el horizonte en el que hay que insertar esta reconstrucción de la macrounidad imperial hispana. Y este marco de inteligibilidad y legitimidad se circunscribe de manera exclusiva a los albores coloniales del expansionismo europeo, eso de "España" como un "imperio," o como una "potencia mundial." El libro de Kamen constituye la narrativa de la intersección de ambas dimensiones disímiles. Tanto el mismo deseo de relación como la exclusividad de este deseo de relación constituyen una anomalía para el contexto académico de los EEUU, que es donde hay que ubicar a quien reseña este libro, al menos de momento, ya que lo que hoy "es" eso de los Estados Unidos, con o sin el aplauso global a principios del siglo veintiuno, queda aquí en la narrativa de Kamen como una de las periferias de esta reconstrucción de una macrounidad transatlántica hispana, portavoz, qué duda cabe, de un Occidente que no es, ni mucho menos, referente habitual, y mucho menos vinculación apetecible, y si no que se lo pregunten a Hardt, Negri, Ferguson, Huntington o Kagan entre otros, para la versión convencional del Occidente angloparlante, para no hablar de la retórica oficial gruesa y grosera de los portavoces actuales de la política exterior norteamericana. Dicho de otro modo, la narrativa de Kamen no tiene una puerta de entrada fácil en los paisajes de desidia asentados con fuerza en tierras "americanas" que tienen que ver con todas aquellas densas texturas diacrónicas anteriores al 1776 que se puedan apartar de la trayectoria hegemónica blanca de habla inglesa, de parentesco más o menos legítimo con la tradición liberal y burguesa, y el último libro de Samuel Huntingon es, una vez más, un hermoso ejemplo tremendamente desasosegante de todo esta normalidad represiva de la vida histórica en los EEUU. Es como si el último imperio, que se sigue considerando una hija más o menos legítima y postcolonial del imperio británico, y de tradición disidente de la Cristiandad protestante viajera entre las aguas frías del Atlántico Norte, funcionase a manera de una enorme aspiradora de la imaginación colectiva, o a manera de un agujero negro cósmico, y absorbiese para sí todas las significaciones dignas de todos los espaciostiempos que le han precedido y que le seguirán. El esfuerzo historiográfico de Kamen nos ayuda a pensar que esto no puede ser así por mucho tiempo.

13 Ibidem, pág. 435. 
Se ha dicho que el eje del libro lo constituye la intersección de "imperio," o "poder," y el impacto de una nacionalidad, "España," en otras. El armazón de esta reconstrucción historiográfica lo constituye la biografía oficial/ista de este super-estado trans- o internacional. ${ }^{14}$ Es así que "imperio" se pueda, y se deba, entender como comunidad, empresa, proyecto o cooperación de tipo internacional, o como una red global/izante de mercado e intercambio de bienes y pesonas. ${ }^{15}$ Estamos, por lo tanto, con una macrounidad multiétnica, multicultural, políglota, transoceánica e intercontinental, donde sin duda alguna se dan intereses dispares, disidencias étnicas, desgarros semióticos, impulsos nacionalistas y tensiones grupales. Y, con estas dificultades, poco valen esloganes fáciles, sean del tipo de las "comunidades imaginadas," u otros.

El énfasis ecléctico para Kamen está en la construcción de esta macroconvergencia comunitaria que parece ahogar toda dicotomía fácil entre "nativismo" y "extranjería," lo cual no quiere decir que este binarismo deje de perder una funcionalidad que parece subyacente al mismo concepto de "imperio" en tanto que "poder" asumido como propio, o no, que se expande y crece, y que se posesiona de lo que no es propiamente suyo. Ferguson incluye sugerentes posibilidades tipológicas de poder imperial in/formal, in/directo, dúctil, etc., que nos parecen válidas también para esta dimensión histórica a la que él no irá nunca con verdadera pasión crítica; ni tampoco Hardt y Negri, quienes, por otra parte, hablan de un desdibujamiento de fronteras, también pertinente para los intereses historiográficos de Kamen como veremos seguidamente.

Y está claro que entre los viajes de Cristóbal Colón y el tratado de París de 1763, ocurrieron muchas cosas, fechas, hechos y nombres que aquí se dan. Una de las mayores virtudes de Empire: How Spain Became a World Power es contarnos de nuevo, con cierta morosidad, algunos de estos sucesos que ya no se suelen presentar con mucho lujo de detalles en las aulas de la escuela secundaria o en las universitarias a ambos lados del Atlántico. O tal vez nos equivocamos. Y esta excentridad, digámoslo una vez más para aquellos que no tengan la dicha —o la desdicha—de la vida cotidiana en los EEUU, tiene que ver con todo lo anterior a la segunda "modernidad" que se suele hacer comenzar de iure o de facto con el tratado de Westfalia en 1648, y el nacimiento oficial del mundo de naciones 
independientes y soberanas, aunque hoy estén un tanto a la deriva. Y es, en la cercanía del diecisiete, donde uno se encuentra el corro de figuras como Lutero, Descartes, Smith, Locke o incluso Hobbes, de predecibles nacionalidades, lenguas y sexo. La narrativa de Kamen queda así en esencia "fuera" de las buenas maneras profesionales de los historiadores convencionales en los EEUU. Del otro lado del Atlántico, la excentricidad de Kamen queda un tanto mitigada con respecto a esta ortodoxia, con la que no se encara y que por tanto no desdice.

La narrativa desmitificadora de todo exclusivismo nacionalista con respecto a este proyecto imperial de Kamen se apoya al menos en cuatro partes. Una primera aseveración sería la complicación de toda dialéctica binarista dicotómica fácil, por no decir chovinista y maniquea, entre imperio y una exterioridad no-imperial, por no decir distancia anti-imperial, o entre lo español/hispano ("Spanish" en inglés), y los que se pueden calificar de extranjeros ("foreigners"). Claro que el criterio nacionalista-exclusivista de creación de semejanzas y diferenciaciones, o de enmarque de problemáticas, no se aplica de manera fácil a los hechos variopintos de los antepasados muertos situados en una matriz imperial o cosmopolita de significación e inteligibilidad como es a la que ciertamente aspira todo imperio que se precie de su nombre. Este desdibujamiento de distinciones binarias, sin embargo, tiene que complicar a la fuerza cierta facilidad de la asignación de centros - militares, epistemológicos, económicos, "culturales," emocionales-a este proyecto de convergencia internacional de la "España imperial". ${ }^{16}$ Kamen mete el sustantivo de "España" como una parte subalterna del todo "imperial" sustancialmente extranjero. Kamen desatiende, así, el nudo conceptual de fundamento economicista de centros y periferias del sistema-mundo (Wallerstein, Arrighi, por ejemplo). Lo que se da en llamar "imperio hispano" [Spanish Empire] es, en realidad, una red de interconexiones que no se llegan a atar cabal o permanentemente alrededor de ningún centro privilegiado. Es así que el eclecticismo metodológico, junto a cierto descentramiento narrativo, anteriormente descritos, se encuentran con la criatura histórica de un imperio hispano descentrado, más "extranjero" o "no-español" que "español" o "nativo". Esta criatura histórica que se suele abreviar como "imperio hispano," la constituye una matriz de intereses que exceden cualquier nacionalidad individualizada. ${ }^{17}$

16 Ibidem, págs. 431, 435-6.

17 Ibidem, págs. 288-9. 
"España,"en tanto que signo nacional aglutinante relativamente reciente para las fechas explícitas incluidas en el título del libro, nunca está en control del "imperio español". ${ }^{18}$ No hay centro, por lo que toda pretensión españolista de exclusividad, ${ }^{19} \mathrm{o}$ de autosuficiencia queda arrinconada, ${ }^{20}$ tanto en relación a la práctica militar, comercial, burocrática, cultural etc. ${ }^{21}$. Toda exclusividad españolista con respecto al "imperio hispano" queda debilitada grandemente, si no inoperante..$^{22}$ Lo de español, o tal vez mejor "hispano," es, por lo tanto, un mal signo, o un signo descriptivo desnaturalizador o insuficiente que no nos ayuda en ningún momento a ver la intimidad de la relación de alianza co-imperial con aliados dentro de una macrounidad "extranjerizante" que lo engloba. Lo "no español" juega, por lo tanto, un papel vital, crucial en el establecimiento del "imperio español". ${ }^{23}$

Una segunda aseveración, coherente con lo anterior, sería la de que no se dio, la "conquista" en especial en relación al continente americano y a las Filipinas. ${ }^{24}$ Kamen se aleja de cualquier tipo de lenguaje absolutizante. Y esto no hay que entenderlo a la manera de un Klor de Alva, ni siquiera como un deseo de blanqueamiento de la "leyenda negra sino, en coherencia con lo anterior, como la virtual imposibilidad de un control militar total, de un disciplinamiento completo, avasallador, de una omnisciencia ubicua por parte de todos los agentes imperiales en todo tiempo y lugar, o de una asimilación hispanizante exitosa por completo, o de una planificación económica perfecta, de una solvencia económica independiente de familias extranjeras. Kamen parece decirnos que todo lo relacionado con el engranaje imperial es más reversible y menos drástico de lo que nos imaginamos. Las distancias son enormes entre Europa, América, Africa y las Filipinas, y el porcentaje de españoles siempre minoritario en relación a poblaciones autóctonas mayoritarias.

Si se habla de imperio, es sólo en la medida en que hay numerosos aliados, amigos, colaboradores, espías, prestamistas, agentes imperialistas entre propios y extraños. Y esto en relación a la vida social total, el sistema de préstamos, los medios técnicos de navegación, el armamento, el sistema esclavista, etc. Es como si el "español" de turno en cualquier teatro

18 Ibidem, pág. 296.

19 Ibidem, pág. 487.

20 Ibidem, pág. 480.

21 Ibidem, págs. $165 ; 264 ; 174-175 ; 502$ y $504-505$.

22 Ibidem, pág. 487.

23 Ibidem, pág. 288.

24 Ibidem, págs. 95-6, 122, 169, 175, 202, 206, 222-3. 
imperial fuese el que llegase el último, tarde y mal a lo que pasase. En este sentido, se da la ineficiencia que se asemeja a virtud: no se puede controlar la administración, ${ }^{25}$ ni las poblaciones ${ }^{26}$ sólo hay apariencia de legalidad, ${ }^{27}$ el comercio está desregulado, ${ }^{28}$ los porcentajes de los extranjeros son siempre altísimos en las tropas imperiales. ${ }^{29}$ Hay tremendos fracasos de todo tipo ${ }^{30}$ ningún "español" va con gusto a la escuela de literaturas, culturas y lenguas extranjeras, sólo los italianos ${ }^{31}$ los españoles tienen muy poca educación, muy malas maneras, se cierran al mundo exterior y no quieren viajar. ${ }^{32}$ El mensaje de Kamen: el imperio hispano no hispaniza, al menos de una manera elegante, seductora, rotunda, total, por los siglos de los siglos, y esto se recalca especialmente en el capítulo once, con su giro lingüístico y su énfasis comunicacional.¿¿No se puede relacionar algo de esto con el actual imperio "americano" que tampoco americaniza de una manera elegante, seductora, rotunda, total, por todos los siglos de los siglos?

La extrema dificultad en la definición de "imperio," o "poder," o, tal vez, "dominación" o "posesión", ${ }^{33}$ consistiría una tercera aseveración. ¿Qué quiere decir esto de "imperio" además de ocupación militar? ¿Qué es lo propiamente imperial y, a la contra, que sería lo anti- y lo no-imperial? La cronología vasta de 1492-1763 nos da, en la narrativa de Kamen, unos bordes borrosos de posibles territorios de lo "hispano," y lo que no lo es, pensemos en toda la América al norte del Río Grande por ejemplo, o las continuadas campañas militares en las líneas de fuego europeas con alianzas entre amigos y enemigos de ida y vuelta. Aquí todos son cortes itinerates, centros desubicados cuyas miras están puestas en Roma o en Italia, ${ }^{34}$ y el dinero viene de familias adineradas en ciudades de lo que sólo posteriormente se llamará Alemania e Italia, y las fronteras que aparecen hoy, desaparecen mañana. ¿Cui bono de esto de imperio? No se sabe bien quién se beneficia de todo este derroche de fuerzas. El imperio parece algo esencialmente fuera de sí, descoyuntando, algo improvisado, o ad hoc, más "on the

\footnotetext{
25 Ibidem, pág. 157.

26 Ibidem, pág. 141.

27 Ibidem, págs. 142-143.

28 Ibidem, pág. 264.

29 Ibidem, pág. 57.

30 Ibidem, págs. 98, 457.

31 Ibidem, pág. 454.

32 Ibidem, pág. 505.

33 Ibidem, págs. 174, 283, 289.

34 Ibidem, pág. 65.
} 
spot," que planificado, ubicado, centrado en un hermoso atlas, ${ }^{35}$ más extraño que propio, más de todos, o de ninguno, que de cualquier impulso nacionalista que se lo quiera atribuir de una manera monopolística, excluyente. ${ }^{36} \mathrm{El}$ imperio no es de nadie. Este es el panorama inquieto y ciertamente incierto que nos presenta Kamen al respecto del imperio hispano de la primera modernidad.

Tenemos la impresión de que eso de "imperio" se comporta, al menos a ratos, como viento burlón con respecto a los mejores esfuerzos de la imaginación histórica de nuestro historiador que no se mete nunca al rastreo microhistórico de las ramificaciones capilares no-institucionales del poder/saber, que diría Foucault. Y si se sugieren las nociones de propiedad, sólo lo hace de pasada en la página 491. Es así que esto de imperio brilla de una manera desconcertante como si fuera una colección de luciérnagas en lugares dispares en la noche de los tiempos. A ratos es como si Kamen mirase las idas y venidas de las historias de estos insectos con los prismáticos, y como si todas estas peripecias de reyes y guerras, conquistadores e indios, escribanos y letrados, comerciantes en ferias de mercado y franciscanos en Nagasaki no tuviese consecuencias perceptibles para el aquí y ahora. En todo caso, está claro que no resulta nada fácil sintetizar en una fórmula portátil eso descomunal de "imperio." De nuevo, entonamos el mea culpa con respecto a lo que puede sonar como una imputación de pobreza conceptual, que tiene que ver más con la dificultad de una síntesis o abstracción convincente que con otra cosa, tan pronto como uno quiere subirse de los particularismos nacionales o nacionalistas a otras visiones más abarcadoras.

Y, finalmente, una cuarta aseveración tendría que ver con la capacidad de colaboración, la adaptación, o la mutabilidad, a veces desconcertante, de los avatares imperiales, siempre incompletos, sea en relación a comunidades convencionalmente llamadas "indígenas", ${ }^{37} \mathrm{o}$ a otras. Es así que el historiar de Kamen no contempla de una manera insistente situaciones de rompimiento permanente, ni cuestiones drásticas, o mutaciones irreversibles: los imperios volando vienen y van, el modelo centralizado de conflictos de clase como motor de la historia se descentraliza en un eclecticismo receptivo a la "diversidad" de "culturas en contacto o conflicto" sin que haya unos orígenes ni unos finales indiscutibles. Lo mejor de esta narrati-

35 Ibidem, pág. 508.

36 Ibidem, pág. 493.

37 Ibidem, pág. 360. 
va es la recreación ocasional de esta multiplicidad de colectividades haciendo lo que pueden por intentar colaborar, beneficiarse, sobrellevar o evitar, si no todas, algunas de estas fuerzas convergentes que damos en llamar "imperios."

Estas cuatro partes de la tesis imperial propician una serie de iluminaciones productivas sobre la presumible "extranjería" —o exteriodidad, o distancia- del imperio "hispano" del "extranjero" Carlos $1,{ }^{38}$ que a su vez nos interpela sobre nuestro "nativismo" aquí y hoy, si es que hubiese alguno. Y esto no es sólo a nivel de nacionalidad a pie de calle, sino a nivel de dónde ubicarse uno en la reconstrucción de la historia que puede llegar a importar, si es que alguna importase. Hay, sin embargo, un uso ocasional, distanciador del deíctico en Kamen: los españoles son "ellos" y están "allî", ${ }^{39}$ aunque cuando este autor no duda en asumir una perspectiva españolista/europeísta. En cualquier caso, el desdibujamiento del binarismo de nativo/extranjero tiene que ver con los amigos, aliados y colaboradores del imperio no deja de sugerir que son los "extranjeros" los que parecen tener la sartén por el mango. Y también, la manufactura cuidadosa de los atlas, las pistolas, las embarcaciones, las lenguas, las monedas, las artes prestigiosas, la poesía, etcétera. Se puede dar la vuelta a la tortilla: los que aquí son extranjeros, allí son nativos, y viceversa. ${ }^{40}$ Así se logra, cuando menos, atenuar todo impulso maniqueísta absolutizante, e incluso relativizarlo, sino diluirlo, en una multidireccionalidad siquiera teórica que sin duda enriquecen el análisis. Por ejemplo, en relación al comercio oficial de este imperio desregulado y la dimensión extra-oficial del mercado negro y de los piratas..$^{41}$ ¿De qué lado se pone el historiador? Por de pronto, de los dos. Y siempre habrá diferencias entre "mi" imperio y el tuyo, "mi" verdad oficial, y la tuya, "mi" luchador por la libertad y "tu" terrorista. ¿Y cómo se negocia esto de "aquî" y "allî" en relación a la inteligencia histórica? ¿Habría posibilidades de residencia permanente entre medias de nativismos y extranjerías, sean éstas del tipo que sean? ¿Y quiénes harían las veces de agentes de aduanas, porteros, policías, colaboradores con la policía, espías, chivatos, soldados y guardianes de prisiones? Se nos antojan unas cuestiones importantes, si bien nos atrevemos a decir que el intertexualismo de Kamen cae en líneas generales en algunas de las (malas) maneras conven-

38 Ibidem, pág. 174.

39 Ibidem, págs. 141, 371-2, 480.

40 Ibidem, pág. 375.

41 Ibidem, pág. 264. 
cionales implícitas de historiador empirista y asume una posición "neutral" u "objetiva". No estamos abogando por una simpleza de posicionamientos, pero sí por ejemplo por una interrogación crítica de la posible conceptualización de poder político que le pueda interesar más, llámese esto imperio, o estado. Esto es lo que Kamen no ofrece del todo.

Por otra parte, Empire: How Spain Became a World Power no socializa su propia producción de conocimiento y no explicita su territorio vital intelectual asumido como propio - con o sin enemigos. Y se quiere tal vez que se crea la ilusión de que la emergencia o visibilidad de la historia transnacional del imperio hispano sea por un posible amor al arte en tardes de ocio. Más bien, sugeriríamos la hipótesis contraria a toda ilusión de distancia: que el conocimiento histórico que se atreve a proponer su propia necesidad o importancia tiene que estar, a la fuerza, latente y tan inseparable y cercano a nosotros como lo está el pulso en las venas de las muñecas y en el cuello. Hay en este libro, lo hemos señalado antes, un abuso de la descripción y un cierto retraimiento de la evaluación de posibilidades descriptivas. Otra manera de decir esto es que no hay una explicitación de los porqués y paraqués de las decisiones que se han tenido que tomar en la escritura de este libro voluminoso. No se entra, en general, en la polémica, con la excepción al respecto de la decadencia imperial hispana en el llamado "Siglo de Oro". ${ }^{42}$ Y aquí creemos ver la sombra de una figura como la de John Elliott, aunque Kamen no lo nombre explícitamente, ni lo incluya en la voluminosa bibliografía. Si la cita inicial de Ramón Carande sienta la pauta para el tono de todo lo que sigue, ${ }^{43}$ Empire: How Spain Became a World Power no es un libro que peque de economicismo. Con o sin alusiones a Tomás de Mercado, se echa en falta algo de los deambuleos de Don Dinero que den algo más de "sustancia" a eso de "imperio."

El positivismo textualista de Kamen posee, al menos a ratos, ciertos resabios de saber de anticuario en esta labor de rescate de las primicias expansionistas de un Occidente hispano. Hay una cierta carencia de un impulso contextualizador comparatista de este imperio con otros proyectos imperiales, o de este proyecto historiográfico con otros que le pueden haber precedido (pienso en Merriman, Pagden, Parker, Thompson, entre tantos otros incluidos en la bibliografía). En cierta manera velada, se asume un marco de visión en general que se puede llamar anglocéntrico o cuando

42 Ibidem, pág. 443.

43 Ibidem, págs. 296-297. 
menos angloparlante. Si se nos permite de nuevo, Kamen se acerca entonces a eso de imperio hispano como un coleccionista de insectos se puede acercar a sus insectos predilectos con morosidad y con gusto pero sin querer en ningún momento sufrir la archiconocida metamorfosis de un infortunado Gregorio Samsa. No se trata de tener que hispanizar al mundo al estudiar el imperio hispano, ni mucho menos de que uno tenga que "ser" eso que uno estudia, o de que tenga que ir de "español" o "españolista" al estudiar el "imperio español," y recuérdese que esta dimensión se está intentando casi siempre extranjerizar, al menos en este libro. La posibilidad de esta riqueza de "ida y vuelta" entre nativismo y extranjería es algo que precisamente echamos en falta en mucho del uso y abuso del lenguaje de "cultura" e "identidad," y esto es lo que queremos designar como una ontologización represiva, llámese estratégica o no, de políticas de identidad, con respecto a la asignación de personalidades institucionales, pero también con respecto a la atribución de legitimidad nacionalista, vinculable o no con proyectos de investigación dentro de una dicotomía velada de "extranjeros" y "nativos". En este sentido sí creemos que Empire: How Spain Became a World Power nos puede ayudar algo en el esfuerzo por intentar insertar una cierta reconstrucción histórica dentro de unos marcos internacionales mayores que nos ayuden a relativizar todos los marcos cognitivos proporcionados por todos los nacionalismos, porque de lo contrario caeremos todos en el saco roto de los olvidos con respecto a las historias de los pueblos menores, ayer imperiales, que sólo a un "ellos" les importará.

Recapitulemos: Empire: How Spain Became a World Power, se ha dicho, constituye una doble retirada, quizás deliberada y ciertamente convencional. Por un lado, constituye una retirada de cualquier tentación de vinculación analógica, o comparativa, con algunas de las posibilidades geopolíticas contextualizadoras más amplias, de marco totalizante o planetario si se quiere. Y por otro, constituye una retirada de todo deseo de explicitación, siquiera tentativo o parcial, de los porqués y paraqués de la epistemología que se asume como propia. Con este gran claro en el bosque, Kamen nos presenta una ontología, o construcción del "ser " del imperio hispano, si bien extranjerizante, ecléctica y descentrada. Esto lo hace nuestro historiador "barcelonés" sin el gesto "dada" de burla, o quiebra, de la matriz cristalina de Occidente, y sin pasar los dedos por los bordes del marco de referencia de la supremacía europea, y sin aparente amargura, resentimiento o dolor para con la relativa excentricidad de eso de "hispano" o eso de "latino," dentro de Europa o en los EEUU. Conviene aclarar que no 
es que no haya una geopolítica ni una epistemología puestas en pie, o varias, que posibiliten esta construcción ontología de un pasado imperial. Lo que ocurre en Empire: How Spain Became a World Power es que no se dice cuáles pueden ser las vinculaciones de estas tres dimensiones disímiles e ineludibles (ontología, epistemología, geopolítica) en relación al espacio-tiempo, o cronotopo, del imperio hispano dentro de la cronología elegida de 1492-1763. En el caso del "extranjero" Kamen, hay un interés profesional continuado por el legado del imperio hispano circunscrito a la cronología citada en relación a la circunstancia inmediata de una Europa barcelonesa que se desdice a principios del XXl de una manera no ambigua de todo tipo de vinculación formal, oficial con este tipo de historias que se pueden llamar del Atlántico Sur, siquiera por contraposición al Atlántico Norte anteriormente delimitado. Y en el caso de este exegeta que se atreve con este quehacer historiográfico, también en una situación de "extranjería" al otro lado del Atlántico, y participando de un interés profesional por el legado del imperio hispano en la cronología citada en una relación inmediata con algunos de los círculos profesionales del mundo universitario en los Estados Unidos, última superpotencia en la actualidad y que se desdice, también a principios del XXl de una manera no ambigua de todo tipo de vinculación formal, oficial con este tipo de historias que se pueden llamar del Atlántico Sur, siquiera por contraposición al Atlántico Norte anteriormente delimitado. El deseo de reconstrucción histórica, o historicidad, buscará siempre el incremento de la persuasión con una serie de juxtaposiciones y paralelos que permitan ver la irradiación de espacios-tiempos siempre ineludiblemente en continua reorganización por los últimos poderes "imperiales" que se puedan asentar sobre la totalidad creciente del planeta. Este paralelo, qué duda cabe, es uno. Otras semejanzas y diferencias se pueden poner sobre la mesa.

Digámoslo de otra manera: Kamen nos presenta su construcción de la ontología del imperio hispano, con los atributos que hemos rastreado antes (extranjerizante, descentrada, no irrevocable, etc.), en toda su soledad o desnudez; pero ésta es una soledad o desnudez de figura de emperador no convincente, ya que no se nos proporcionan las ropas epistemológicas necesarias para su presentación en sociedad, y también sin una circunstancia espacio-temporal cambiante, y sin un paisaje geopolítico explícito, claro, que no puede detenerse en 1763, tanto en relación a los intentos de conceptualización de eso de "imperio" como a la posibilidad teórica de fuerzas contrarias, como pueden ser nacionalismo, anti-imperialismo, impulsos 
anticivilizatorios, sin olvidarnos de las agonías de historicidad que puedan dificultar las tareas y los posibles vuelos de la razón histórica.

La voz narrativa de Kamen, si bien ambiciosa y totalizante con respecto al imperio hispano, no parece tener interés por convocar una multidimensionalidad desigual de perspectivas múltiples que vaya y venga por todas las transformaciones pertinentes que involucran a Cataluña, Reino Unido, España, Europa, los Estados Unidos, el continente americano desde 1492 hasta la actualidad como si esta no fuese crucial factor epistemológico, geopolítico para su propio quehacer historiográfico. Kamen allana estas geografías reales e imaginarias. Y este allanamiento no es convincente. Calificamos, de nuevo, las reservas, que estamos poniendo sobre la mesa al lado de este libro ciertamente ambicioso y útil: no es que haya que convocar toda la historia universal en todo momento narrativo, lo cual es ciertamente descabellado; pero lo que sí hay que hacer es posicionarse de alguna manera, o de cuando en cuando, de manera cuidadosa $u$ oblicua, o explícita y valiente, o como sea, con respecto a algunos de los ángulos de visión de esta multidimensionalidad de grupos sociales con sus reyes, meninas y cortesanos, pero también con la chusma en las calles y las ratas de las alcantarillas. No hay "ser" (social) sin esta reconstrucción de los beneficios y perjuicios de las epistemologías convencionales, paisajes geopolíticos de ayer y de hoy, valles y montañas, coros de polémicas, rueda de problemáticas, maniobras, estrategias, deseos y desidias interpretativas, centros de crisis global e ínsulas extrañas, que, sin lugar a dudas, involucran todos los esfuerzos de Kamen y también los nuestros.

Hay, a la contra, en Empire: How Spain Became a World Power un adelgazamiento pudoroso de la modalidad de enunciación historiográfica que se retrae, convencional o deliberadamente, de cuestiones "metahistóricas" mayores. El ovillo narrativo descentrado de Empire: How Spain Became a World Power sólo alude de pasada a un centro, llámese "imperio" o "España," pero siempre para mantenerlo vacío, como si no se pudiese volver a un centro o no se quisiese llenarlo; como si el eclecticismo metodológico antes aludido no supiese como zanjar o no quisiera resolverse en un "monismo" vinculable a toda teoría singular o totalizante, llámese a este monoteísmo, o teoría, o síntesis o abstracción. Y se puede pensar en los trabajos inspiradores de un Roger Chartier dentro de esta modalidad interrelacional-intertextualista por ejemplo. Si todo es red, interconexión, mediación, ${ }^{44}$ sea formal o informal,

44 Ibidem, pág. 474. 
oficial o para-oficial, mercado blanco a plena luz del día o mercado negro, ${ }^{45} \mathrm{si}$ todo es inmanencia, entonces parece que a lo más que puede llegar la inteligencia histórica es a poner sobre la mesa una buena descripción de estas redes espacio-temporales, a menudo desconcertantes, lo cual no es poco.

Kamen no busca en ningún momento querer "subir" a un nivel axiológico de abstracción "superior," en donde se puede habilitar, si quiera tentativamente, una tienda de campaña a manera de lugar utópico de discriminación de la importancia dispar de las filosofías de las historias (imperiales). Queda, por lo tanto al final, la duda sobre la ganancia posible del monumental esfuerzo de esta reconstrucción imperial, sobre todo si tenemos en cuenta algunas de las figuras de talla mencionadas en este artículo-reseña, algunas de ellas también mencionadas por el propio Kamen. Nos quedamos, de momento, al final, con la asociación de "imperio," o poder político globalizante, y un crecimiento de la condición de "extranjería" contra todo impulso nativista o nacionalista de patrimonialismo exclusivista, y con toda las fallas, los silencios, la extraoficialidad, la informalidad o la mutabilidad que se le quieran imputar.

\section{Sobre ontologia represiva, o anti-hispanismo.}

Se puede calificar el último libro de Samuel P. Huntington como un producto miserable, por partida doble, porque desprecia lo que ignora, y porque explicita una serie de repudios desde posiciones de fuerza. Who are We? The Challenges to America's National Identity ${ }^{46}$ pone sobre la mesa los antagonismos y las miserias, los miedos - fingidos o no-y los desprecios, las intencionadas ignorancias de los más fuertes en lo que ya es un comienzo de siglo tormentoso. Es mi generación la que tendrá que lidiar con los intereses más o menos velados, pero también con contracciones y miedos, retraimientos y actitudes beligerantes dentro de señalados sectores intelectuales en los Estados Unidos, y también a pie de calle. Y ¿cómo abrir puertas al campo? Tal vez tenga uno que atrapar el unicornio de lo "hispano" por la cola de la Hispanofobia, o la historia que importa entre las grietas de la historia oficial de este país que compartimos con Huntington. El presente libro de Huntington, profesor del Departamento de Gobierno en la

45 Ibidem, pág.. 472.

46 Huntington, Samuel P.: Who are We? The Challenges to America's National Identity, New York, Simon \& Schuster, 2004. 
Universidad de Harvard, y figura muy conocida por su anterior libro The Clash of Civilizations and the Re-Making of the World Order (1996), constituye en esencia un uso de razón estratégica circunscrita a círculos oficiales. Huntington busca proveer un servicio fiel $-\mathrm{o}$ servil $-\mathrm{a}$ los intereses de política exterior estadounidense asumidos como propios. Esto se lleva a cabo con eso no-obvio que se tiende a llamar "cultura" e "identidad." Avisamos ya que uno tendrá que andarse con mucho cuidado en estos predios porque estos dos signos sirven aquí, más bien, como excusa. No nos despistemos: Huntington no quiere pasar a la historia como el nuevo Weber, o el nuevo Kant, o el nuevo Braudel. Lo que él quiere ser, y posiblemente lo sea, es convertirse en el experto exegeta de todas las incertidumbres en los nuevos tiempos tras la guerra fría. Sus fórmulas culturalista-civilizatorias querrían tomar el testigo de la mano de George Kennan, el padre (de la patria oficial) con su fórmula de bipolaridad USSR-U.S. y la teoría de la contención del poder soviético. Sea lo que sea eso de "cultura," este girasol estará siempre de cara al sol de los intereses inmediatos y los asuntos acuciantes de la política exterior de la última superpotencia.

Vivimos un momento de gran desorden a todos los niveles y donde nadie parece saber a ciencia cierta por qué camino tirar. El nuevo siglo se presenta como todo lo contrario a la autocontención del binomio bipolar: un no-disimulado unipolarismo aparentemente omnipotente, si bien dando palos de ciego, con una autopercepción de vulnerabilidad; ${ }^{47}$ un desdibujamiento de fronteras de todo tipo, también a nivel de planes de investigación y estudio, paisaje de guerras virtuales, sin declaraciones formales ni muertos visibles, al menos dentro de los EEUU, sin victorias claras, contra enemigos no convencionales. La guerra se presenta, al menos dentro de ciertos círculos por los que se mueve Huntington, como la modernidad, es decir como la condición ineludible y deseable que somos, en alusión al interrogante del libro, y como catástrofe cotidiana que nos constituye ("catástrofe," en el sentido de un Paul Virilio. ${ }^{48}$ "Cultura" —o su prima hermana, "identidad"- - es entonces este gozne de puerta (social, política, económica, histórica) que se cierra con un portazo. Lo que se busca es galvanizar una colectividad llamada "nacional" con apelaciones al miedo y a la seguridad y así intentar apuntalar la entelequia o eternidad de una supremacía estadounidense. Cualquier alternativa a esto constituye, al menos para nuestro

47 Ibidem, pág. 336.

48 Virilio, Paul: A Landscape of Events, Massachusets, MIT, 2000. 
autor, lo impensable, lo indeseable otro de la ontología estatista gubernamental. Pero el siglo veintiuno nos pone mala cara: mundo el nuestro donde primeros, segundos y terceros mundos viven ayuntados de manera promiscua - e irregular - para confusión para todos. El tiempo y el espacio se pliegan, se escogen y se estiran, se convierten en un ovillo, se rompen y se olvidan. ${ }^{49}$ Las tradiciones de antaño están todas patas arriba, los centros, descentrados y los particularismos todos en pie de guerra, todas las ideologías huecas, la psique colectiva reprimida. ${ }^{50}$ Así, y no de otra manera, hay que entender todos los vivas a la individualidad como centro de la vida estadounidense: como un "divide y vencerás" en una nación de casi 300 millones de personas. ${ }^{51}$ Who are We? The Challenges to America's National Identity nos pinta un cuadro ciertamente desolador por partida doble de virtud y carencia. Lo que sigue a la guerra fría, no es ahora ni caliente ni frío, sino todo lo contrario: guerra visual con sus muertos de este lado escondidos y con muertos del otro lado que ya no se cuenta, guerra de comandos, de antagonismo explícito al Islam y a los hispanos en los EEUU, de cierta deseuropeanización de los EEUU — producto históricosocial de la emigración europea- y de una convergencia, llámese globalización si se quiere, que constituye un reto para todos. Huntington da pruebas de las contracciones, los retraimientos, los apartamientos y los llamados patriotas —o patrioteros y xenófobos-a la renovación "cultural," siempre dentro de un formato nacional, amenazada, según Huntington, por enemigos internos y externos. ¿Pero se trata, en verdad de interrogar la ontología del "ser"? ¿Se trata de contrastar conceptualizaciones de lo que puede constituir eso de la "identidad"? ¿Se trata en verdad de atisbar la serie de relaciones del Ser" y de la "Nada"? ¿Y tenemos que darnos todos fieles y dóciles a eso de "nación"? La sociología vulgar de Huntington, aupada en un positivismo de encuestas y estadísticas, dirá que sí, pero no al modo filosófico.

Según Huntington, no se trata de consultar enciclopedias o diccionarios de filosofía y ver cómo se puede empezar a pensar bien eso de "identidad," "ontología," "cultura," o lo que sea.—El carácter híbrido, desaliñado de las ciencias sociales, al menos según nuestro autor casi octogenario, se dirige al gran público. Y, por lo tanto, lo que no se quiere es quedarse

49 Huntington trata de la época dorada del patriotismo estadounidense durante 1860-1960 en la pág. 120.

50 Ibidem, pág. 61.

51 Ibidem, pág. 53. 
prendado de una complejidad conceptual que nunca se prestará bien a intereses coyunturales de política exterior y doméstica de la última administración estadounidense, y mucho menos a un uso publicitario fácil o comercial que pueda encaramarse al estatus de best-seller en la lista de ventas del New York Times. Who are We? The Challenges to America's National Identity constituye, así, una especie de libelo, incluso una filípica que busca un efecto de "electro-shock cultural." Y este golpe de efecto se persigue con una vulgarización deliberada del pensamiento que no duda en chapotear en las aguas del cálculo egoísta de la demagogia política por parte de sectores cercanos al partido republicano. Vulgarización quiere aquí decir uso de estadísticas y encuestas, siempre dentro de un formato nacionalista o de publicaciones de prensa, mayormente estadounidense. También quiere decir un uso simplista, grueso y grosero del inglés, cosa curiosa con respecto a alguien que rebosa un monolinguismo feroz. Plebeyización quiere decir también el recurso al sicologismo con respecto a fenómenos históricos, sociales y políticos ${ }^{52}$ pero casi siempre dentro de contextos oficiales y de estrategias militares (los primeros libros de Huntington son de este tipo). Se puede entender precisamente el recurso al sicologismo - $\mathrm{O}$ al anti-racionalismo - como bagaje propio de la pobreza conceptual que acompaña al signo de "cultura," lo cual no impide que se abandone por otro más convincente. "Cultura" — al igual que "libertad" o "democracia"— gusta precisamente por vacío, versátil, fácil, tic bien aprendido, bien educado, bienpensante, gesto ligero, eufemismo conveniente, convencional ortodoxia. Esto es lo que los abogados de la Realpolitik, lo que se llama "realist power politics en los EEUU, hacen en público estos primeros años del nuevo siglo." ${ }^{33}$

Lo que se traen entre manos es el empobrecimiento conceptual del inglés para interrogar las tensiones de su propia realidad inmediata y más cercana, cuando menos para la contemplación de realidades más distantes como puede ser el mundo del Islam, demonizado sin tapujos. Y lo que se busca es des-socializar y deshistorizar al lenguaje y al pensamiento. La moralina oficialista de "los buenos y los malos," pensemos en la retórica del actual presidente George W. Bush, se contrapone al rechazo del "moralismo" del derecho internacional de ciertos círculos intelectuales, y éste al "moralismo profundo," llamado "religioso," del público estadounidense, uno de los pueblos "más religiosos del mundo". ${ }^{54}$ Pero hay que desconfiar

52 Véase sobre todo las páginas 21, 118 y 258.

53 Ibidem, pág. 79.

54 Ibidem, pags. 270,82 y 340. 
siempre de estos llamados a la piedad. En este libro, la apelación a la religión suena a maquiavelismo de falsa piedad y a manufactura mediática de docilidad con respecto a los postulados oficialistas. ${ }^{55} \mathrm{Nada}$ hay de apología huera de la tradición anglosajona que la acerque amorosamente a un lector curioso. Aquí no hay nada que se acerque a la curiosidad intelectual genuina por el hecho religioso, por ejemplo el impresionante proyecto ecuménico de un Eugenio Trías en La Edad del Espíritu, o la emoción genuina del cine de un Passolini, o un Tarkovskij, o la música de un Arvo Part. Lo de "protestantismo disidente" es aquí insípido. Lo de "cultura anglosajona," figurines de cartón piedra. No hay ningún esfuerzo por recreación de paisajes ni ningún esfuerzo por persuadir a un lector interesado. Esto de "religión" se acerca más a algunas de las imágenes de la Pasión de Mel Gibson que exige una actitud masoquista de autocastigo para propios y extraños que a una visión franciscana de fragilidad cósmica. El uso de "religión" de Huntington, cercano a sectores conservadores ${ }^{56}$ nos pone los pelos de punta con sus visiones apocalípticas de fin del mundo de "los otros." Hay algo en Who are We? The Challenges to America's National Identity de fe a duras penas, como la del soldado romano que va a la guerra contra los bárbaros contra su voluntad y con todas las reticencias de quien ya no se cree su propia civilización, como en la película Gladiator. Algo de esta actitud vital mezquina, de impulso reacio, crispado, "a la contra" se da en este libro que repudia toda alusión a la ciencia política, a la interrogación de la historia antes de la paz de Westphalia, además de ignorar olímpicamente todo cuestionamiento — llamémoslo filosófico—de sus propias premisas de conocimiento. El uso sociológico, digamos, es "periodístico," incluso "reporteril" de porcentajes, estadísticas, encuestas, revistas de think tanks, declaraciones de figuras conocidas o desconocidas al respecto de temas mayores (el autor agradece un tanto exageradamente a sus asistentes del Book Team). Se da por hecho el dicho de los variados personajes, algunos con nombres y apellidos, pero no siempre: si los estadounidenses usan mucho la bandera de las estrellas y las barras tricolores, y dicen que son muy patriotas y muy religiosos, esto va a la misa de la excepcionalidad nacional, y se presenta, a manera aristotélica, como evidencia de que los más fuertes son los más virtuosos. La prosa, en cualquier caso, ha pasado por muchos filtros, ojos y manos, y se presta a simplificaciones delibera- 
das, o gestos anti-intelectuales. Esto será lo que pasee sus reales por revistas, medios de comunicación de masas y librerías del tipo de Barnes and Noble. El mensaje fundamental de este "académico patriota" ${ }^{57}$ es, como estamos viendo, tremendamente desasosegante. Se trata de ofrecer, una vez más, la pócima de la disciplina y castigo con o sin "cultura" e "identidad," lenguaje, por cierto, usado más bien por grupos contestatarios. Huntington presenta en esencia un mensaje asimilacionista ${ }^{58}$ y represivo de cualquier diferencia o "diversidad" con respecto a un modelo estándar angloparlante, de tradición anglosajona, o mejor anglo-germana, aquí sin vitalidad, y vinculada, siquiera débilmente a la tradición de un cristianismo de grupos protestantes, y de blanqueamiento de la diversidad racial. Y toda esta maravilla se realiza en aras de una supremacía de los EEUU, cueste lo que cueste, con respecto al resto del mundo que, colocado siempre en una posición subordinada, parece importar bastante poco. EEUU es así el portavoz oficial de la "Europa" y el "Occidente" que el "multiculturalismo" está atacando. ${ }^{59}$ De nuevo, la Europa y el Occidente de Huntington, con sus ribetes neo-Straussianos, dan miedo por lo beligerante e intolerante. Y esta "política de la identidad" con los señuelos de cultura y nación de aquellos que "se identifican con su país", ${ }^{60}$ una forma boba pero insidiosa de hablar y de pensar, es la que vierte aceite hirviendo sobre los desosiegos que tienen que ver con algunos de los retraimientos oficiales, institucionales propios de los albores imperiales de esta primera mitad del siglo veintiuno. ${ }^{61}$ Es como si no se hubieran aprendido algunas de las lecciones históricas de la intolerancia oficial entre las tres religiones (cristiandad, judaísmo, islamismo) propias del imperialismo hispano, al menos según las lecturas de un Américo Castro, sólo por poner un ejemplo, o peor todavía, como si los expertos y managers, apologetas y agentes oficiales del último imperio sufrieran de la saña de la ignorancia y del gusto del autismo o la pérdida de memoria histórica, de no querer saber y no querer aprender de algunas de las desconcertantes panorámicas post-imperiales de otro lugar y tiempo no tan distantes.

En Who are We? The Challenges to America's National Identity.Hay, en verdad, una sensación de dejá vu Hay algo de nostalgia, de impulso

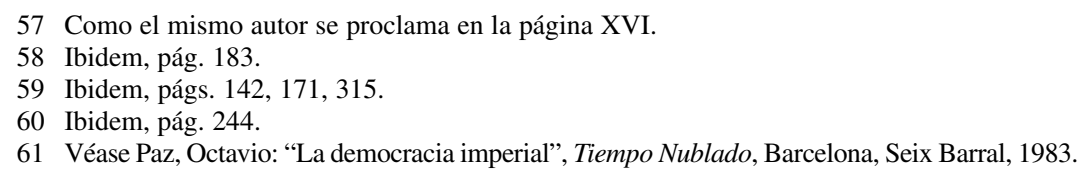


"retro" — pero no chic—y de que todo tiempo pasado fuera mejor, lo cual es mentira, y que la década de los 1960 vino para estropearlo todo. Y lo que se estropeó fue una sensación de invulnerabilidad de los EEUU en la cúspide de su poderío cultural, económico y militar. ${ }^{62}$ Este libro desapacible se suma así, tarde y mal, al coro de voces como Allan Bloom, The Closing of the American Mind, Arthur Schelinger, The Disuniting of America, o personajes dudosos como Allan Bennett y Lynne Cheney, o incluso el Achieving our Country de Richard Rorty entre otros. Se trata de insistir en la nación propia desde una posición de fuerza de superpotencia subyugadora de un mundo poco amable. ${ }^{63}$ A la sombra del 9/11, los "poco amigos" son siempre "ellos," claro, pero también, en un interesado nudo del pañuelo, los emigrantes, los extranjeros, los multiculturalistas, los cosmopolitas, los intelectuales poco patriotas, los moralistas del derecho internacional, los hombres de negocio de multinacional, los mexicanos, los que hablan español, los que no se quieren asimilar. . . Las yuxtaposiciones lo dicen todo, especialmente en los finales de capítulo. ${ }^{64}$ No hay medias tintas. Aquí no hay gusto canclinesco por hibrideces de ningún tipo. No hay generosidad ni aperturas a lo impredecible o lo desconocido. Aquí no hay deleite ni exhuberancia. No hay lenguas extranjeras, ni culturas ni literaturas. No hay ningún deseo por extender la ciudadanía romana a todo el planeta (lo cual podría ser una cierta solución). Huntington está, al contrario, asustado - o finge susto- ante algunas de las tremendas transformaciones dentro y fuera de su país. Sólo hay que rascar un tanto los eufemismos al uso ordinario de esta prosa de brocha gruesa, y grosera, para ver como "lo que somos" se construye siempre a la contra de "lo que decimos no ser," o mejor de lo que "son ellos." Aquí no hay sensibilidad de existencialismo historicista de estancias, circumstancias ni existencias que valgan. Esto es "ser" y "no ser," al lado de la última tecnología militar y a la sombra de las dos palmeras reinas de la apelación al miedo y el fetiche de la seguridad.

Who are We? The Challenges to America's National Identity busca así, de una manera displicente y despiadada, regenerar una nacionalidad "acosada" tras los espectaculares sucesos del 11 de Noviembre, la fecha se menciona repetidas veces a manera de campanadas de alarma. Huntington

62 Hay una coincidencia entre el vigor vital de Huntington, con 40 años, y el clímax de la superpotencia de los EEUU, al menos según las fechas de alguien como Immanuel Wallerstein, citado por cierto, mezquina y oblicuamente en las páginas 310 y 405.

63 Como el mismo afirma, "unfriendly", en la página 109.

64 Ibidem, págs. 138, 177, 256, 291. 
no duda en explicitar una serie de "retos" — como lo dice el título del libro- que "nos" ayuden a constituirnos como "estadounidenses." Y hay que hacer notar el uso eufemístico de aludir indirectamente a lo que no nos gusta, o de nombrar veladamente a los adversarios políticos, y el lector atento tendrá que acudir a las notas al final del libro para ubicar algunas de las referencias o verificar algunos de los nombres aludidos de manera indirecta. Aunque hay, claro, una gradación que va de la formulación de unos "otros" o "ellos," a los "retos" de los "extranjeros," o los "enemigos." Entre éstos, figuran: el enemigo externo del Islam, ${ }^{65}$ el enemigo interno de los "hispanos," especialmente los de origen mexicano, ${ }^{66} \mathrm{el} \mathrm{multiculturalismo}$ dentro de algunos sectores universitarios ${ }^{67}$ el cosmpolitismo de algunos grupos directores del mundo de los negocios y las multinacionales ${ }^{68}$ los sectores defensores del derecho internacional, ${ }^{69}$ y fenómenos como el cosmopolitismo, las diásporas, los emigrantes con o sin papeles, los que tienen o quieren tener una doble nacionalidad,$^{70}$ los agentes de los gobiernos extranjeros que logran influir la toma de decisión nacional, ${ }^{71}$ el "terrorismo," etc. Hay un gesto demagógico, por parte de Huntington, que podemos calificar de "fuenteovejunesco" en el sentido de que nuestro autor no duda en ponerse al lado de lo que quiere —o dice querer-el "público" estadounidense, al menos según los sondeos, estadísticas, declaraciones en prensa, etc. y marcadamente en contra de estos "retos" anteriormente citados. Huntington dice estar con, por y para el bien del público estadounidense alienado por un sistema de democracia no representativo. ${ }^{72}$ Hay un gesto típicamente estadounidense, a menudo proveniente de sectores intelectuales, al menos según la sociología del tipo de John Galbraith y Richard Hofstadter, y este es el caso de Huntington, que se sirve intencionadamente de un sospechoso anti-intelectualismo demagógico, para crearse un espacio y conseguir así unos ciertos beneficios a corto plazo.

Este "público" permanece, según él, a la contra, patriota, religioso, convencido de los "éxitos" de la asimilación y fiel al centro constitutivo de la cultura e identidad estadounidense, que se identifica, sin sorpresas, como

65 Ibidem, pág. 188.

66 Ibidem, capítulo 9, pág. 316.

67 Ibidem, págs. 171, 269, 315.

68 Ibidem, pág. 269.

69 Ibidem, pág. 271.

70 Ibidem, pág. 204.

71 Ibidem, págs. 282,287

72 Ibidem, pág. 335. 
el mundo anglosajón, la disidencia protestante, el uso del inglés, la ética del trabajo, el "idealismo" político estadounidense, etc. El truco identitarioculturalista de Who are We? The Challenges to America's National Identity se puede desvelar así: nosotros somos lo que somos en la medida en que no somos otros, y lo decimos, y en la medida en que somos fieles a aquellos valores proclamados por los poderes oficiales (curiosamente no hay llamadas a regenerar la estructura gubernativa o los tribunales de justicia, todos los demonios parecen habitar los sectores educativos y universitarios y algunos de los despachos del mundo de las multinacionales). Huntington nos saca del armario la ropa carcomida de los abuelos de los tiempos, la ideología WASP [white, anglo-saxon protestant]. Pero este gesto intelectual "retro" en un autor casi octogenario lo hace con lo que se podría describir como el toque "chic" de un énfasis en lo lingüístico-cultural-identitario. La insuficiencia de la persuasión del credo político oficial estadounidense, ${ }^{73}$ lo que podríamos llamar el debilitamiento de la comunidad de creencia, ${ }^{74}$ en la ideología única del liberalismo del diecisiete, da paso a la modalidad sicológica, blanda de la modalidad cultural en un momento post-ideológico: La "cultura" o lo distintivo de la sociedad de individuos, ${ }^{75} \mathrm{o}$ las maneras habituales de vida humana desligadas de cualquier "lugar", ${ }^{76}$ desatadas de cualquier suelo histórico, desubicadas en la marcha global de la historia que se desconoce y se desprecia. "Cultura" se asemejaría a los anuncios multi-raciales de Benetton, suena al mundo de la moda, a vida fácil, casi al Gilles Lipovetsky de La Edad del Vacío ${ }^{77}$ si no fuera porque estamos del lado de Marte del Atlántico, y no del allá de Venus, y nuestro experto pone sobre la mesa un monolingüismo feroz coherente con un repudio de hibridez de ese presumible centro estadounidense de raigambre anglo-germana con cualquier otra modalidad "cultural." El "ser" de Huntington no es meramente descriptivo, sino que anuncia el deber ser normativo. No hay sin embargo atracción persuasiva de los "bárbaros" con una sensualidad de pensamiento, todo lo contrario: Who are We? The Challenges to America's National Identity constituye una esencialización represiva de eso de "América" autosuficiente, aislada de, y encumbrada por, la historia universal, al menos desde la segunda guerra mundial.

73 Ibidem, pág. 19.

74 Ibidem, pág. 67.

75 Ibidem, pág. 21.

76 Ibidem, pág. 49.

77 Lipovetsky, Gilles: La Edad del Vacío: Ensayos sobre el Individualismo Contemporáneo, Barcelona, Anagrama, [1983], 2002. 
Lo "excepcional" de este estereotipo asumido como propio, a la altura tardía de los tiempos inestables del siglo XXl, es lo famélico y descarnado, pero también lo insidioso de la ortodoxia de esta "idea" no exenta de represión psíquica. ${ }^{78}$ Dentro de los EEUU, se elogia a los estadounidenses y se les dice que son los más lindos, inteligentes, religiosos, fuertes, etc. de la historia del mundo, y éste es un mecanismo de disciplina y de castigo que los diferencia y los aísla del resto del mundo. Y con el resto del mundo se mantiene una relación ni fría ni caliente, pero beligerante. Entonces de lo que se trata, al menos desde estructuras oficiales de poder y conocimiento en unos momentos delicados como el actual, es de producir unos chivos expiatorios que ayuden a consolidar el totem del miedo y a apuntalar el tabú de la seguridad. En este paisaje ciertamente sobrecogedor, Huntington se presta de mil amores a este juego político, agarradito de las manos de las dos primas hermanas de la "cultura" y la "identidad."

Si The Clash of Civilizations and the Re-Making of the World Order propone un ordenamiento geopolítico de la totalidad del mundo siguiendo, al menos en cierta manera, los delineamientos culturalistas-civilizatorios ya existentes en la historiografía ambiciosa de un Toynbee o un Braudel, si bien dentro de una matriz hegeliana-churchilliana, Who are We? The Challenges to America's National Identity cierra puertas, se retira del mundo ancho y ajeno, se retrae, se repliega, con un mensaje igualmente inapelable, brutal. Los que no tienen la dicha de "ser" estadounidenses tienen - tenemos todos-que aprender a sensibilizarse con el impacto de la violencia de este vaciamiento de la escritura y el pensamiento acerca de la historia imperial dentro de las propias fronteras de los EEUU. El "nosotros" de Huntington resulta así un constructo "monoteísta" de deidad, estadonación, cultura central, uso de lengua, etc. poco apetecible, poco deseable, al menos para quien escribe estas páginas, en el sentido de que repudia explícitamente una serie de "ellos." Como tal, el gesto de Huntington es explícitamente político. Y su libro se posiciona sin miramientos. "Civilización" se baja del caballo volador, se quita las gafas de amplias visiones diacrónicas, los estudios comparados, las pompas y se queda en este último libro en "cultura." "Capitalismo," por otra parte, brilla por su ausencia, en un gesto típicamente estadounidense que rehúye el nombre del sistema político-económico vigente hoy, y por lo tanto lo encubre, lo naturaliza, y lo justifica siquiera por defecto. Y es así que tenemos un silencia-

78 Ibidem, pág. 61. 
miento del sistema y la verborrea de las palabras "cultura" e "identidad." Hay, por lo tanto, que echar a andar una cierta hermenéutica de la sospecha con estas ontologías culturalistas-identitarias esencialistas.

"Cultura" refuerza el "Credo" oficial — nada que ver con la noción de "creencia" orteguiana que se acerca a lo que Huntington intenta perseguir con su defensa de "cultura central anglosajona"-y esto de "cultura" se equipara aquí con "identidad nacional." El monismo de Huntington quiere sugerir la equiparación perfecta entre los tres conceptos favoritos (cultura, nación e identidad). No hay dialéctica hegeliana de superación de términos positivos y negativos, ni supuestas subidas a otro nivel más abarcador. Entre el "ser" estadounidense y la "nada" no-estadounidense, no hay "nada," o tal vez el abismo. O mejor dicho, hay "retos," "extranjeros," "enemigos" y "traidores" dentro y fuera de las fronteras de los Estados Unidos, con o sin recuerdos del Orwell de 1984. El mensaje xenófobo es claro, aun con todos los eufemismos puestos en uso.

Huntington se juntaría a la mesa con Parménides antes que con Heráclito. El "ser" estadounidense "es," en definitiva, una serie de sustantivos con la sugerencia de un fondo de permanencia y lo peligroso, en Huntington, es que la descripción de esencias se vuelve, casi imperceptiblemente, un deseo de normatividad represiva de esencia única. La esencia se da en la especificidad intolerante de formato nacional construido sobre una (ilusión de) continuidad que rehúsa contemplar sus opuestos, discontinuidades, orígenes plurales, finales posibles, etc. En Who are We? The Challenges to America's National Identity sólo el "ser" es, y lo es como el amo "es" con respecto al esclavo: a expensas de, o contra los "retos" de, o provocaciones de, o insubordinaciones de, o la mala educación de, un "no ser." Hay una profunda desconfianza ante el mundo aglutinante más allá del formato nacional. El signo de "nación"es este deseo de esencia o sustancia en unos momentos de insuficiencia de los formatos nacionales. Así habla Huntington de la "crisis" de desnacionalización mundial en la página 14, que pretende solucionar con un reconcentrado nacionalismo "identitario" y "cultural," La identidad del "ser" consigo mismo es la identidad formal u oficial a la que se desea supeditar todas las otras. La gran dificultad será en cómo delimitar ese ser nacional dentro del espacio-tiempo de la historia de la humanidad. La historia que le importa a Huntington empieza en los siglos XVll y XVlll, aun cuando el comienzo auténticamente significativo y tenso para él sean los años 1960. No hay postmodernidad posible, pensable a la eterna modernidad supremacista estadounidense, a diferencia de 
autores como Wallerstein, Jonathan Schell, Charles A. Kupchan entre otros. Sin teleologías, Huntington se presenta como un reformista de su propia nacionalidad dañada, según él, por enemigos externos e internos. Who are We? The Challenges to America's National Identity quiere ser un proyecto reformista, de vuelta a las raíces, de renacimiento. Su proyecto es, por lo tanto, de nation-building, aun cuando este término sólo se use habitualmente para intervenciones "humanitarias" en otros países. Estados Unidos constituye aquí una ilusión oficialista de mismidad —o insistencia en la semejanza, o poso de permanencia - cuya igualdad culturalista-identitaria se halla, como Ariadna y el minotauro en el laberinto de los tiempos desordenados, según Huntington, siguiendo el hilo rojo WASP trans-substancializado. El lenguaje sugiere una ontologización represiva de la vida social y política, pero repetimos que este libro no va por filosofías, sino por sociologías vulgares. La cultura es ornamental, la inteligencia es estratégica, institucionalista y oficialista, el uso de razón, razón de estado, y nación, o imperio, totalidad, aun cuando la propuesta final de Huntington sea una regeneración nacionalista $— \mathrm{o}$ un imperialismo reacio—en la línea "república, no imperio" de un Pat Buchanan.

Pero hay más: el signo de "cultura" "es" aquí la lengua del pueblo, las creencias religiosas, los valores sociales y políticos, los patrones de comportamiento y lo que se asume colectivamente como bueno y malo, apropiado o inapropiado, y también la objetividad del mundo institucional en la medida en que puede, o quiere, hacerse eco de un mundo subjetivo. ${ }^{79}$ Esta es la vuelta de tuerca crucial: "cultura" "es" también "línea de fuego" en un mundo post-ideológico ${ }^{80}$ Con o sin un deliberado empobrecimiento retórico, el comienzo del capítulo décimo lo dice bien a las claras: "cultura [es] fuente de identidad en un mundo desideologizado" cuando se están borrando las distinciones entre lo nacional y lo transnacional. ${ }^{81} \mathrm{El}$ mundo de Huntington se alimenta de estrategias militares y es, sin lugar a dudas, despiadado, de noche de lobo hobbesiano donde el conflicto es necesario y deseado. La guerra es necesaria - y deseada - porque ayuda a recobrar los olvidos de la "identidad nacional." Sin ella, esta unidad identiaria nacionalculturalista se debilita, se rompe. Lo de "islámico," y lo de "hispano" funcionan así como el signo "Albania" en la película Wag the Dog. Es el chivo expiatorio —ahí fuera o aquí dentro- que galvaniza las energías

79 Ibidem, pág. 30.

80 Ibidem, págs. 258 y 301.

81 Ibidem, págs. 296, 21, 288, 301, 304, 337, 340. 
hacedoras de una colectividad que de otra manera no se puede constituir como tal. No se trata aqui de reconstruir la historicidad compleja, tensa, de un Lutero, un Hobbes, un Locke, un Adam Smith. Sino de decir que los estadounidenses son muy trabajadores y tienen una gran ética de trabajo, según las aserciones de las estadísticas. Y de que son muy religiosos. Y de que izan las banderas y que son muy patriotas. Su ontología esencialista culturalista-identitaria estadounidense, dentro de una sociología de corte positivista vulgar, no se atreverá nunca $-\mathrm{y}$ con buenas razones - a un cotejo interdisciplinar, y mucho menos a un enmarque geopolítico, aun viniendo este libro después del conocido The Clash of Civilizations and the Re-Making of the World Order, y casi 50 años después de unos comienzos en círculos estratégico-militares. Who are We? The Challenges to America's National Identity es la escatología lógica de orígenes en The Soldier and the State: the Theory and Politics of Civil-Military Relations (1957) y The Common Defense: Strategic Programs in National Politics (1961). De aquellos polvos, estos lodos.

Le basta señalar una serie de enemigos para seguir en la brecha. ${ }^{82}$ La pretensión de "neutralidad", en relación al posible (mal) trato de la dimensión "no-estadounidense" [un-American], no se sostiene en ningún momento en relación a nuestro académico autocalificado como patriota. Sólo hay que leer con cierto cuidado la elección de adjetivos, la selección de las personas y las citas, la proveniencia del material y los contextos. Aun cuando Huntington escamotee su propio pronunciamiento, su posicionamiento asimilacionista, supremacista está fuera de toda duda dentro de esta visión "diplomática" de línea dura de la historia universal. El uso ornamental de productos literarios o filmicos sirve para ilustrar un mensaje militarista, xenófobo, de tremenda violencia en relación a un "agente del mal" externo, como la retórica reciente lo nacionaliza en Iraq, Iran y Corea del Norte, o en referencia a un "juez español" que se atreve contra el General Augusto Pinochet, pero también contra disidentes internos, como pueden ser Martha Nussbaum, Immanuel Wallerstein, William Flores y Rina Benmayor, entre otros. ${ }^{83}$

Queda ya un poco más claro entonces lo que el signo "cultura" puede llegar a significar en los años desconcertantes de la post-guerra fría, postUnión Soviética y post 9-11, al menos para académicos del tipo de

82 Ibidem, pág. 258.

83 Ibidem, págs. 271, 270, 309 y 316. 
Huntington, que no dudan en ponerse las ropas populistas anti-intelectualistas cuando les puede convenir. "Cultura" es la hilacha que cuelga de todos los "post-," con la posible excepción de post-imperialismo. Con una actitud explícita de supremacismo monolingue, lo que se da en llamar "English-only "America First," "identidad [nacional]" es aquí un insidioso eufemismo, que delata la autopercepción de vulnerabilidad por parte de ciertos sectores sociales ante ciertas transformaciones imparables dentro y fuera de los EEUU. Entre ellas, la hispanización, fenómeno que se resiente en Who are We? The Challenges to America's National Identity de una manera explícita (hay que retrotraer el nombre de "hispano" a los deseos de clasificación de la administración de Nixon). Hay que agradecer lo explícito de este repudio, sobre todo cuando se tiene la impresión de la deshonestidad de otros repudios a la callada, también dentro del contexto universitario estadounidense (por cierto, departamentos de español y portugués no figuran en el radar de Huntingon, excepto las inclusiones 'periodísticas' al deseo de bilinguismo de Ilans Stavans y Ariel Dorfman. ${ }^{84}$ En cualquier caso, parece que el estado de Florida, Miami en concreto, y mucho de la costa sudoeste ya son tierra perdida.$^{85}$ La Hispanización avanza como una invasión inexorable, y películas de ciencia ficción como Strange Days nos pueden ayudar a imaginar un Los Angeles post-apocalíptico como el que le aterra a Huntington y a otros. ¿Qué sería lo "no-cultural" en el marco de visión de Huntington y de qué nos serviría? ¿Sería lo "contracultural" todo lo que él repudia como "retos" a un posible recentramiento de la conciencia nacionalista reformulada dentro de una matriz identitaria-culturalista esencialista necesariaente algo deseable para nosotros? No se atisba una calma a corto plazo, al menos tras la lectura de este libro último del autor de niñez en Astoria, Queens, Nueva York. Who are We? The Challenges to America's National Identity es un intento feroz de secuestro del lenguaje de la "identidad" y la "cultura" de las "minorías." Esta propuesta es por ello una "contra-política de identidad" proveniente de un sociologismo vulgar propio de unas ciencias sociales ancladas en un monismo institucionalista-oficialista, articulado siempre dentro de un horizonte nacionalista intolerante o excluyente. Esencialismo estratégico por parte de Huntington que se lanza contra una dimensión mayor, vinculada a los cosmopolitismos, los emigrantes, los terroristas, etcetera, y también

84 Ibidem, págs. 317 y 136.

85 Ibidem, págs. 203, 221, y247. 
contra todas las desobediencias internas, llámense resistencias anti-asimilacionistas de los multiculturalismos particularistas por parte de los sectores s (mal-)llamados "hispanos," o por otros grupos. Americanización, al menos según Huntington, significa el éxito de la violencia síquica que reduce la sociedad, la historia y la "cultura" a unos logos con unas luces de colores chillones, pero todo con escasa vida, con poco calor. No nos creemos el centro de seducción de una cultura anglosajona para los EEUU de nuestro autor que nunca la quiere ni puede levantar a los ojos de los lectores atentos de una manera persuasiva.

La "América" de Huntington son unos Estados Unidos displicentes, autistas, ayunos de intercambio con el mundo más grande, reacios al esfuerzo por querer conocer su propias transformaciones y las ajenas. Hay en Who are We? The Challenges to America's National Identity una actitud de cerrazón de mente típicamente norteamericana que desprecia lo que ignora desde una posición identitaria-culturalista de identificación con los postulados oficialistas de la geopolítica gubernamental. La nación estadounidense se construye así como una excepcional alienación excepcional y de proporciones mayúsculas displicente con respecto a todas las otras dimensiones nacionales.

En relación al sentido represivo de la tesis asimilacionista-supremacista de Huntington, se nos ocurre, al menos al final, aligerar y "jugar" por ejemplo musicalmente con el sinsentido "dada" de "Psycho Killer" de David Byrne, o introducir el bilinguismo de "Dance and dense denso" de un grupo como Cóctel Molotov, o el experimentalismo híbrido de "Radio Bemba Sound System" de alguien como Manu Chao: "Whenever, whatever" con la tesitura de Huntingon, con o sin Shakira (y que aquí ponga el lector sus sugerencias favoritas). En relación con esta textura aseverativa configuradora de un antihispanismo mezquino, podemos contestar como Ulises al Polifemo de un solo ojo, que no somos nadie. Y tal vez sea éste un buen plan de huida: dejar deseada y deseante la crisis del centro del "ser". 